\title{
Umbilical Cord Blood Lipid Profile in Healthy Neonates in Iran
}

\author{
Asadollah Kermani (iD) ${ }^{1}$, Kokab Namakin (iD ${ }^{2,}{ }^{,}$, Gholam Reza Sharifzadeh (iD) ${ }^{3}$ and Gholam Reza Faal (iD) ${ }^{1}$ \\ ${ }^{1}$ Department of Pediatrics, Birjand University of Medical Sciences, Birjand, Iran \\ ${ }^{2}$ Cardivascular Disease Research Center, Birjand University of Medical Sciences, Birjand, Iran \\ ${ }^{3}$ Department of Epidemiology, Birjand University of Medical Sciences, Birjand, Iran \\ "Corresponding author: Department of Pediatrics, Birjand University of Medical Sciences, Birjand, Iran. Email: d_namakin@yahoo.com
}

Received 2019 December 14; Revised 2020 April 20; Accepted 2020 May 01.

\begin{abstract}
Background: Coronary heart diseases (CAD) and their risk factors are among the major causes of death in Iran. Since these risk factors begin to develop early in life, it is vital to diagnose those newborns at high risk of CAD.

Objectives: The present study investigated the umbilical cord blood lipid profile of term and preterm neonates.

Methods: In this cross-sectional study, the lipid profiles of 292 neonates, of which 276 were term and 16 preterm, were examined at a teaching hospital.

Results: The lipid profile results of total cholesterol, triglycerides, high density lipoprotein, and low density lipoprotein were 69.8, 34.9, 23.6, and 31.5 in term neonates and 80.5, 25.5, 25.1, and 38 in preterm neonates, respectively.

Conclusions: According to the current paper, the lipid profiles of eastern Iranian neonates were similar to those reported in global studies. Moreover, except for triglycerides in the female neonates, lipid profiles were significantly higher among the male neonates.
\end{abstract}

Keywords: Lipid Profile, Umbilical Cord Blood, Coronary Artery Disease, Neonate

\section{Background}

Coronary heart diseases (CAD) are fatal diseases worldwide (1). Generally, the high incidence of CAD is due to genetic and environmental risk factors (2). Scientific experiments have indicated that atherosclerosis and CAD may appear in childhood, but can also develop for decades without any clear symptoms (2-5). The level of serum lipids and lipoproteins in childhood can predict profiles in adolescence.

The primary events of CAD, i.e. cardiovascular atherosclerosis, are closely related to the concentration, metabolism, and abnormality of lipoproteins (6-10). Based on some evidence, this relation forms at birth. Studies have shown that measuring these markers in the cord blood of neonates can identify those at higher risk of CAD in their future life (11).

Although the normal range of lipoproteins has been determined for developed countries (4) there has not been enough research addressing this issue for developing nations, such as Iran. Of the studies conducted, there were many differences in results, which can be explained by genetic, environmental, and physiological factors (1, 12-16). As the present study was conducted almost a decade after previous works, nutritional patterns and lifestyles would have since changed. In addition, there are cultural indica- tors within Iran that differ according to region, such as residence near an international border, lack of resources, and nutritional patterns. The current research does not resemble other studies in that it is noticeably different in regard to inclusion and exclusion criteria and the number of samples. Finally, it must be noted that such studies should be repeated so that results can be generalized for the society as a whole.

The triglyceride levels reported by studies conducted in India (17), some regions in Iran $(1,18)$ and Poland (19) were much higher than standard levels worldwide.

\section{Objectives}

Consequently, the current research aimed to more precisely repeat the sampling process by featuring healthy neonates. As a result, the TG levels observed in the present work's experiments did not differ from those in international references.

\section{Methods}

The current epidemiological study of 292 healthy newborns was conducted from December 2018 to April 2019 at Vali-e-Assr Hospital, a teaching hospital in Birjand, eastern 
Iran. The research was approved by the Ethics Committee of Birjand University of Medical Sciences and a written informed consent was obtained from all parents. At least 285 samples were statistically required. The inclusion criteria were: singleton pregnancy, no congenital anomalies, a 5-minute Apgar score of 9 or 10, and no asphyxia. The exclusion criteria were: infants with intrauterine growth retardation (IUGR), history of maternal hypertension, hyperlipidemia, CAD, diabetes, drug use (except for vitamins, folic acid and iron) and/or smoking either before or during the pregnancy, preeclampsia or eclampsia, instrumental deliveries, and any deliveries outside of Vali-e-Assr Hospital. Birth weights were measured by an electronic scale (Seca Medical Scales and Measurement Systems, Birmingham, United Kingdom).

According to the WHO, preterm is defined as babies born alive before 37 weeks or the completion of 259 days of pregnancy (20). The present study used the first day of the last menstrual period to determine gestational age and this was confirmed by ultrasound. The healthy neonates were divided into two groups according to birth weight: group 1 for normal birth weight $(2,500$ to $4,000 \mathrm{~g})$ and group 2 for low birth weight (less than 2,500 g). The newborns were also split into two groups according to gestational age: mature (term) for those born at 37 to 42 weeks and immature (preterm) for births at less than 37 weeks. There were neither high birth weight nor post term neonates included, which was probably due to the exclusion of diabetic mothers. Mothers with a background of hypertension and other diseases were not included. The average age of the pregnant mothers was 28.27 years. Five $\mathrm{ml}$ of umbilical cord blood was collected from the placental end of the umbilical vein and then centrifugation separated the serum. The serum lipid and lipoprotein levels were measured via an enzymatic method with an auto analyzer (Hitachi, Tokyo Japan). The samples were then analyzed to determine the lipid profile, namely total cholesterol (Chol), triglycerides (TG), high density lipoprotein (HDL), and low density lipoprotein (LDL).

Statistical analysis: Data were analyzed using SPSS 18 for Windows (SPSS Inc, Chicago, IL, USA). Results were expressed as mean \pm standard deviation (SD). The Chisquare and Mann-Whitney tests performed statistical comparisons. $\mathrm{P}<0.05$ was considered statistically significant.

\section{Results}

We studied a total of 292 healthy neonates [145 (49.7\%) females and 147 (50.3\%) males]. The mean age of the mothers was $28.27 \pm 5.9$ years (minimum 15 and maximum 45 years). The mean birth weight was 3132.6 grams. The lipid profiles of the newborns, consisting of Chol, TG, HDL, and LDL, were 70.1, 34.6, 23.7, and 31.7, respectively.

There were positive relationships between the weight, HDL, and TG of the newborns and gestational age (Table 1). However, only the HDL correlation was significant ( $P$ $=0.031$ ). As for differences between the male and female neonates, the males had a higher weight than the females, but the females showed significantly higher levels of Chol, HDL, and LDL (Table 2).

Table 1. Evaluation of Correlations Between Gestational Age and Birth Weight Based on the Neonates' Lipid Profiles

\begin{tabular}{lcc}
\hline Lipids Variation & Gestational Age $(\mathbf{N}=\mathbf{2 9 2})$ & Birthweight $(\mathrm{N}=\mathbf{2 9 2})$ \\
\hline HDL, mg/dL & $\mathrm{r}=0.06, \mathrm{P}=0.28$ & $\mathrm{r}=0.13, \mathrm{P}=0.031^{\mathrm{a}}$ \\
LDL, $\mathbf{m g} / \mathbf{d L}$ & $\mathrm{r}=0.06, \mathrm{P}=0.34$ & $\mathrm{r}=0.05, \mathrm{P}=0.39$ \\
TG, $\mathbf{m g} / \mathbf{d L}$ & $\mathrm{r}=0.27, \mathrm{P}<0.001^{\mathrm{a}}$ & $\mathrm{r}=0.08, \mathrm{P}=0.17$ \\
Chol, mg/dL & $\mathrm{R}=0.06, \mathrm{P}=0.28$ & $\mathrm{r}=0.02, \mathrm{P}=0.74$ \\
\hline
\end{tabular}

Abbreviations: Chol, total cholesterol; HDL, high density lipoprotein; LDL, low density lipoprotein; n, number; P, probability value; r, R-squared value; TG, triglyceride.

${ }^{\mathrm{a}}$ Table indicates a positive and meaningful correlation between HDL and birth weight and between TG and gestational age.

\begin{tabular}{|c|c|c|c|}
\hline Sex Variation & Males $(N=147)$ & $\begin{array}{c}\text { Females }(N= \\
145)\end{array}$ & $t$-test \\
\hline Birthweight, g & $3197.8 \pm 381$ & $3066.5 \pm 427$ & $\mathrm{P}=0.006, \mathrm{t}=2.77$ \\
\hline Chol, mg/dL & $66.9 \pm 15.7$ & $73.3 \pm 20.6$ & $\mathrm{P}=0.03, \mathrm{t}=2.59$ \\
\hline $\mathrm{TG}, \mathrm{mg} / \mathrm{dL}$ & $35.2 \pm 16.5$ & $34 \pm 15.3$ & $\mathrm{P}=0.49, \mathrm{t}=0.68$ \\
\hline HDL, mg/dL & $22.4 \pm 8$ & $25 \pm 9$ & $\mathrm{P}=0.01, \mathrm{t}=2.59$ \\
\hline LDL, mg/dL & $30.1 \pm 9.9$ & $33.4 \pm 11.7$ & $\mathrm{P}=0.009, \mathrm{t}=2.61$ \\
\hline \multicolumn{4}{|c|}{$\begin{array}{l}\text { Abbreviations: Chol, total cholesterol; HDL, high density lipoprotein; LDL, low } \\
\text { density lipoprotein; n, number; P, probability value; r, R-squared value; TG, } \\
\text { triglyceride. } \\
\text { aValues are expressed as mean } \pm \text { SD. } \\
\text { b Table shows that the weight of male newborns was noticeably higher than } \\
\text { that of the females. However, the Chol, HDL, and LDL levels of the female } \\
\text { neonates were significantly higher. }\end{array}$} \\
\hline
\end{tabular}

There were eight $(2.73 \%)$ infants in the immature (preterm) group and 284 (97.27\%) in the mature (term) group. TG was significantly higher among the mature neonates, while there was no difference in the other lipid profiles of both groups (Table 3 ).

There were 16 (5.47\%) low birth weight and 276 (94.53\%) normal birth weight neonates. No significant statistical differences were observed between the mean lipid profiles of low birth weight and those of normal weight neonates (Table 4). 
Table 3. Comparison Between the Birth Weight and Lipid Profiles of Mature (Term) and Immature (Preterm) Neonates ${ }^{\text {a, b }}$

\begin{tabular}{lccc}
\hline $\begin{array}{l}\text { Maturity } \\
\text { Variation }\end{array}$ & $\begin{array}{c}\text { Immature }(\mathbf{N}= \\
\mathbf{8})\end{array}$ & $\begin{array}{c}\text { Mature }(\mathbf{N}= \\
\mathbf{2 8 4})\end{array}$ & t-test \\
\hline Birth weight, $\mathbf{g}$ & & $3149.3 \pm 397.6$ & $\begin{array}{c}\mathrm{P}<0.001, \mathrm{t}= \\
4.26\end{array}$ \\
\hline Chol, mg/dL & $80.5 \pm 29.9$ & $69.8 \pm 18.1$ & $\mathrm{P}=0.11, \mathrm{t}=1.61$ \\
\hline TG, $\mathbf{m g} / \mathbf{d L}$ & $25.5 \pm 8.4$ & $34.9 \pm 15.9$ & $\mathrm{P}=0.016, \mathrm{t}=3$ \\
HDL, mg/dL & $25.1 \pm 10.3$ & $23.6 \pm 8.6$ & $\mathrm{P}=0.94, \mathrm{t}=0.47$ \\
\hline LDL, $\mathbf{m g} / \mathbf{d L}$ & $38 \pm 17.7$ & $31.5 \pm 10.6$ & $\mathrm{P}=0.09, \mathrm{t}=1.66$ \\
\hline
\end{tabular}

Abbreviations: Chol, total cholesterol; HDL, high density lipoprotein; LDL, low density lipoprotein; n, number; P, probability value; r, R-squared value; TG, triglyceride.

${ }^{\mathrm{a}}$ Values are expressed as mean $\pm \mathrm{SD}$.

${ }^{\mathrm{b}}$ The above data presented a significantly higher TG average in mature (term)

infants, but no noteworthy differences in other profiles.

\begin{tabular}{|c|c|c|c|}
\hline Weight Variation & $\operatorname{LBW}(N=16)$ & $\operatorname{Normal}(N=276)$ & $t$-test \\
\hline CHOL, mg/dL & $71.7 \pm 30.4$ & $70 \pm 17.7$ & $\mathrm{P}=0.72 \mathrm{t}=0.36$ \\
\hline TG, mg/dL & $36.3 \pm 16.4$ & $34.5 \pm 15.9$ & $P=0.67 t=0.43$ \\
\hline HDL, mg/dL & $20.9 \pm 11.5$ & $23.8 \pm 8.4$ & $P=0.19 t=1.3$ \\
\hline LDL, $\mathrm{mg} / \mathrm{dL}$ & $35.7 \pm 18.2$ & $31.5 \pm 10.3$ & $\mathrm{P}=0.13 \mathrm{t}=1.5$ \\
\hline
\end{tabular}

Abbreviations: Chol, total cholesterol; HDL, high density lipoprotein; LBW, low birth weight; LDL, low density lipoprotein; n, number; P, probability value; r, R-squared value; TG, triglyceride.

${ }^{a}$ Values are expressed as mean $\pm S D$.

${ }^{\mathrm{b}}$ There were no significant statistical differences between the mean lipid pro-

files of LBW and those of normal weight neonates.

\section{Discussion}

The current research showed that neonate lipid profiles in Birjand differed from those in other regions of Iran $(1,18)$, a difference probably due to the contrasting life styles of these areas. However, the TG, Chol, and LDL levels in the present study's mature (term) neonates are the same as those reported in international references (4). The research results by Kelishadi et al. (21), Badiee and Kelishadi (1), and Aletayeb et al. (18), though, indicated higher level of lipids in Iranian neonates. The current work's TG levels were almost half of those reported by other studies in Iran. In comparison with research conducted internationally, the present paper's TG levels were considerably lower than in the Omar et al. (22), Jain and Sogani (17), and PacKozuchowska (19) studies. Interestingly, the lipid profiles of the healthy neonates and mothers enrolled in the current research were similar to those reported in global references. When analyzing the differences in results between the present work and other studies, it can be assumed that the same measurements for evaluation were employed, such as the Apgar scores 9 and 10. Therefore, the dissimilarity in findings may be explained by some variables that produced the abnormal TG levels and by the special health conditions of the neonates studied.

The HDL level reported in the current study was noticeably lower than the reference level (4). However, it was similar to that of other studies $(1,17-19,22,23)$, perhaps because of the factors of malnutrition and poor socioeconomic conditions.

The present research found that female neonates had considerably higher Chol, HDL, and LDL levels than did the males, a finding similar to that reported in the Badiee and Kelishadi study (1). In the current work, the TG levels were the same in both genders, just as Badiee and Kelishadi (1) and Aletayeb et al. (18) had observed.

In the current study, the TG level of the immature (preterm) neonates $(\mathrm{P}=0.016)$ was significantly lower than that of the mature (term) neonates. The Chol, HDL, and LDL levels in the immature (preterm) subjects were similar to those in the Pardo et al. (23) and Aletayeb et al. (18) studies, which had reported higher but not statistically distinctive results.

The Chol, TG, and LDL levels of low birth weight neonates in the present research were higher than those of the normal birth weight newborns. However, similar to the Aletayeb et al. (18) study, the HDL of low birth weight neonates was lower in comparison to the normal birth weight subjects, but not significantly. This may indicate that serum lipids are not related to birth weight. However, more prospective studies with more samples are necessary to identify a possible relation.

The current study's limitations were its relatively few samples, few immature (preterm) and mature (term) samples, few low birth weight neonates, and an absence of high birth weight neonates, all of which would have contributed to a more comprehensive evaluation.

\subsection{Conclusions}

The present paper has shown that the lipid profiles of umbilical cord blood in eastern Iran are the same as those reported worldwide, with the exception of lower HDL levels.

The present research found that female neonates had considerably higher Chol, HDL, and LDL levels than did the males, a finding similar to that reported in the Badiee and Kelishadi study (1). In the current work, the TG levels were the same in both genders, just as Badiee and Kelishadi (1) and Aletayeb et al. (18) had observed.

The current research reported a marked gender difference in lipid profiles. Except for the same TG level among both sexes, the Chol, HDL, and LDL levels in female neonates were considerably higher. Therefore, the present paper's lipid profiles of umbilical cord blood in eastern Iran concur with those found worldwide. 
Based on its results, the current study recommends further longitudinal studies on how cord blood lipids differ among various ethnic populations in different regions.

\section{Acknowledgments}

The authors are sincerely grateful for all the facilities provided by the Vice Chancellor for Research Affairs of Birjand University of Medical Sciences, for the studies by researchers and publishers from which the current work benefited. Thanks to Victoria Baldrama Azghandi for proofreading and improving the manuscript. And, last but not least, for the mothers and babies who kindly participated in the study

\section{Footnotes}

Authors' Contribution: Study concept and design: AK and KN. Analysis and interpretation of data: AK, KN, and GS. Drafting of the manuscript: AK. Critical revision of the manuscript for important intellectual content: AK and KN. Statistical analysis: GS.

\section{Conflict of Interests: None.}

Ethical Approval: The ethical code was IR.BUMS.REC. 1397.255.

Funding/Support: Deputy of Research and Technology Birjand University of Medical Science dunded this research.

\section{References}

1. Badiee Z, Kelishadi R. Cord blood lipid profile in a population of Iranian term newborns. Pediatr Cardiol. 2008;29(3):574-9. doi: 10.1007/s00246-007-9149-0. [PubMed: 18046597].

2. Bigazzi R, Zagato L, Lanzani C, Fontana S, Messaggio E, Delli Carpini $S$, et al. Hypertension in high school students: Genetic and environmental factors: The HYGEF study. Hypertension. 2020;75(1):71-8. doi: 10.1161/HYPERTENSIONAHA.119.13818. [PubMed: 31760884].

3. Pradeep P, Arunkumar T, Sundari S. Comparative study of cord blood lipid profile in preterm and post term neonates. Int J Contemp Pediatr. 2019;6(6). doi: 10.18203/2349-3291.ijcp20194626.

4. Ryles L, Neal WA. Disorders of lipoprotein metabolism and transport. In: Kliegman RM, editor.. Nelson Textbook of Pediatrics; 2020. p. 270548.

5. McGill JHC, McMahan CA; Group Pdoaiyr. Determinants of atherosclerosis in the young. AmerJCardiol.1998;82(10):30-6. doi:10.1016/S00029149(98)00720-6.

6. Bastida S, Sanchez-Muniz FJ, Cuena R, Perea S, Aragones A. High density lipoprotein-cholesterol changes in children with high cholesterol levels at birth. EurJPediatr.2002;161(2):94-8. doi:10.1007/s00431001-0863-y. [PubMed: 11954759].

7. Sueta D, Yamamoto E, Sato M, Sato T, Fujisue K, Arima Y, et al. Temporal trends in atherosclerotic risk factors in school children- findings from 20-year surveillance. CircJ.2020;84(3):524-8. doi:10.1253/circj.CJ19-0828. [PubMed: 32023564].
8. Hudson SE, Feigenbaum MS, Patil N, Ding E, Ewing A, Trilk JL. Screening and socioeconomic associations of dyslipidemia in young adults. BMCPublic Health.2020;20(1):104. doi: 10.1186/s12889-019-80999. [PubMed: 31992243]. [PubMed Central: PMC6986140].

9. Michos ED, McEvoy JW, Blumenthal RS. Lipid management for the prevention of atherosclerotic cardiovascular disease. $N$ Engl J Med. 2019;381(16):1557-67. doi:10.1056/NEJMra1806939. [PubMed:31618541].

10. Lalitha.S S, Vasanthan M, Birundha S, Rajalakshmi K, Balasubramanian A. Studying atherogenic index of plasma and lipoprotein (A) for better cardiac risk stratification in public health. IntJ Clin Biochem Res. 2020;7(1):76-9. doi: 10.18231/j.ijcbr.2020.016.

11. Srinivasan SR, Berenson GS. Serum apolipoproteins A-I and B as markers of coronary artery disease risk in early life: the Bogalusa Heart Study. Clin Chem. 1995;41(1):159-64. [PubMed: 7813072].

12. Collings PJ, Farrar D, Gibson J, West J, Barber SE, Wright J. Maternal physical activity and neonatal cord blood lipid levels: Findings from a prospective pregnancy cohort. J Phys Act Health. 2020;17(2):236-41. doi: 10.1123/jpah.2019-0550. [PubMed: 31945742]. [PubMed Central: PMC7212008].

13. Knuiman JT, Westenbrink S, van der Heyden L, West CE, Burema J, de Boer J, et al. Determinants of total and high density lipoprotein cholesterol in boys from Finland, The Netherlands, Italy, the Philippines and Ghana with special reference to diet. Hum Nutr Clin Nutr. 1983;37(4):237-54. [PubMed: 6643128].

14. Khalil A, Gupta S, Madan A, Venkatesan M. Lipid profile norms in Indian children. Indian Pediatr. 1995;32(11):1177-80. [PubMed: 8772866].

15. El-Hazmi MA, Warsy AS. Evaluation of serum cholesterol and triglyceride levels in 1-6-year-old Saudi children.J Trop Pediatr. 2001;47(3):1815. doi: 10.1093/tropej/47.3.181. [PubMed: 11419685].

16. Akuyam SA, Isah HS, Ogala WN. Evaluation of serum lipid profile of under-five Nigerian children. Ann Afr Med. 2007;6(3):119-23. doi: 10.4103/1596-3519.55722. [PubMed: 18240500].

17. Jain S, Sogani S. Evaluation of lipid profile and apolipoproteins in cord blood from tribal and nontribal population of Udaipur region, India. Int J Reproduct Contracept Obstet Gynecol. 2015:1825-30. doi: 10.18203/2320-1770.ijrcog20151268.

18. Aletayeb SMH, Dehdashtian M, Aminzadeh M, Emami Moghaddam AR, Mortazavi M, Azizi Malamiri R, et al. Correlation between umbilical cord blood lipid profile and neonatal birth weight. Pediatr Polska. 2013;88(6):521-5. doi: 10.1016/j.pepo.2013.08.004.

19. Pac-Kozuchowska E. Evaluation of lipids, lipoproteins and apolipoproteins concentrations in cord blood serum of newborns from rural and urban environments. Ann Agric Environ Med. 2007;14(1):25-9. [PubMed: 17655173].

20. Chambless L, Keil U, Dobson A, Mahonen M, Kuulasmaa K, Rajakangas AM, et al. Population versus clinical view of case fatality from acute coronary heart disease: results from the WHO MONICA Project 1985-1990. Multinational monItoring of trends and determinants in cardiovascular disease. Circulation. 1997;96(11):3849-59. doi: 10.1161/01.cir.96.11.3849. [PubMed: 9403607].

21. Kelishadi R, Hashemipour M, Sarraf-Zadegan N, Amiri M. Trend of atherosclerosis risk factors in children of Isfahan. Asian Cardiovasc Thorac Ann. 2016;9(1):36-40. doi: 10.1177/021849230100900110.

22. Umar LW, Aliyu IS, Akuyam SA. Evaluation of lipid profile in cord blood of full-term Nigerian newborn infants. Sub-Saharan Afr J Med. 2017;4(1). doi: 10.4103/ssajm.ssajm_44_16.

23. Pardo IM, Geloneze B, Tambascia MA, Barros-Filho AA. Atherogenic lipid profile of Brazilian near-term newborns. Braz J Med Biol Res. 2005;38(5):755-60. doi: 10.1590/s0100-879x2005000500013. [PubMed: 15917957]. 